\title{
A INSERÇÃO DE ESTUDOS CRÍTICOS ANIMAIS EM INSTITUIÇÕES DE EDUCAÇÃO SUPERIOR
}

\section{THE INSERTION OF CRITICAL ANIMAL STUDIES IN HIGHER EDUCATION INSTITUTIONS}

\author{
CASTELLANO, Maria \\ mcastelbr@gmail.com \\ USP - Universidade de São Paulo \\ SORRENTINO, Marcos \\ sorrentino.ea@gmail.com \\ USP - Universidade de São Paulo
}

\begin{abstract}
RESUMO Os "Estudos Críticos Animais" compõem um campo de conhecimento interdisciplinar relativamente novo na educação no Brasil e têm as relações entre humanos e os outros animais como seu foco central. Em alguns países o campo encontra-se bastante avançado e vem se fortalecendo inclusive por suas interrelações com disciplinas que questionam outras formas de opressão - tais como os estudos de gênero, étnicos e GLBTs. Oriundo de uma pesquisa de pósdoutoramento, o presente artigo aborda as possibilidades de formação de pessoas nessa área e sua inserção em Instituições de Educação Superior no Brasil. Parte dos subsídios aqui apresentados provêm da análise da experiência de quatro universidades da América do Norte (uma nos EUA e três no Canadá).
\end{abstract}

PALAVRAS-CHAVE: Estudos Críticos Animais. Formação. Instituições de Educação Superior. Institucionalização.

ABSTRACT Critical Animal Studies is a relatively new interdisciplinary field in Brazilian education, having as it central focus the relations between humans and the other animals. In some countries the field is considerably advanced, and has been strengthened in part because of its interrelationships with disciplines that challenge other forms of oppression-such as gender, ethnic and LGBT studies. Resulting from a post-doctoral research, this paper approaches the possibilities of educating people in this field, as well as the insertion of such training in higher education institutions in Brazil. Part of the subsidies presented here came from the experience of four universities in North America (one in the U.S. and three in Canada).

KEY-WORDS: Critical Animal Studies. Education. Higher Education Institutions. Institutionalization.

\section{INTRODUÇÃO}

Nos dias atuais, questionamentos estão ocorrendo em diversos pontos do globo sobre assuntos de ordem ética, tais como corrupção, homofobia, xenofobia, questões de gênero, organização social e política, entre outras. São temas que 
abordam relações de opressão cuja ocorrência é facilitada por assimetrias de poder. O presente artigo trata de uma dessas questões, que se refere às relações entre animais ${ }^{1}$ humanos e não humanos - sobretudo, aquelas que se configuram como opressão do primeiro grupo em relação ao segundo.

Nas últimas décadas este tema tem se ampliado de forma crescente, desde a publicação do livro Animal Liberation por Peter Singer, em 1975. No Brasil, essa expansão tem sido mais notória a partir do século XXI, após a tradução de alguns livros importantes para a área (FELIPE, 2007). Desde então o tema começou a circular via internet, em salas de aula do ensino médio e superior (ainda que timidamente) e em publicações e trabalhos acadêmicos, recebendo assim alguma atenção de grupos específicos. O crescimento do ativismo relacionado à causa também tem contribuído para a ampliação do tema, inserindo-o na mídia de forma mais direta e levando-o assim a setores mais amplos da sociedade.

Internacionalmente, a causa animal vem sendo considerada uma importante questão de justiça social. Tem sido analisada frequentemente de forma interseccional, em sua relação com outras formas de opressão e movimentos sociais, buscando estabelecer, a partir da libertação animal, um movimento holístico de libertação total para animais humanos, não humanos e para o planeta (CORMAN, 2011; HUMES, 2008; KAHN, 2008; KAHN; HUMES, 2009).

No contexto acadêmico, a análise da complexidade das relações entre humanos e os outros animais em países de fala inglesa vem sendo chamada de Human-Animal Studies (HAS) ou Critical Animal Studies (CAS), e é abordada por meio de diversas áreas do conhecimento, tais como a antropologia, a filosofia, as artes, o direito, o trabalho social e a literatura, entre outras (DEMELLO, 2010). Segundo esta autora, este é um dos campos de pesquisa com crescimento mais rápido na atualidade. Existem, hoje, mais de duzentas disciplinas em universidades na América do Norte sendo ministradas sobre relações humanos-animais, e cerca

\footnotetext{
${ }^{1}$ No presente texto utilizamos, em diversos momentos, o termo 'animais' para fazer referência aos animais não humanos. Esta opção foi feita apenas para conferir maior fluidez ao texto, sendo que consideramos, entretanto, que não há uma linha divisória clara que separe os humanos dos outros animais.
} 
Atos de Pesquisa em Educação - ISSN 1809-0354

Blumenau, v. 10, n.2, p.654-680, mai./ago. 2015

DOl: http://dx.doi.org/10.7867/1809-0354.2015v10n2p654-680

de outras cem em faculdades de direito, além de doze programas universitários dedicados ao tema e diversos centros a ele associados em campi universitários.

O presente artigo parte da consideração de que este tema é uma das mais importantes questões éticas e de justiça social com a qual temos que lidar na atualidade. Isso se deve não apenas à intensidade da violência envolvida em suas práticas e à quantidade de seres sencientes ${ }^{2}$ que são vitimados por elas, mas também à profundidade da mudança paradigmática que a questão demanda. Assim, tem o objetivo de analisar os elementos que contribuem para a formação de sujeitos comprometidos em atuar pelo fim da opressão entre animais humanos e não humanos, com foco nas possíveis contribuições de Instituições de Educação Superior (IES) para esse processo.

Uma vez que o tema é relativamente novo no campo da educação no Brasil, o texto se inicia com uma breve contextualização, trazendo algumas das principais questões relacionadas à opressão entre animais humanos e não humanos. A segunda seção apresenta considerações sobre a pesquisa e o método utilizados para levantar e analisar os resultados que serão apresentados na sequência. Por fim, a terceira seção analisa possibilidades de se contribuir para a formação de sujeitos comprometidos com o avanço em direção a relações mais justas entre animais humanos e não humanos, com foco nas IES. Chamaremos aqui de sujeitos animalistas as pessoas que se sensibilizam e se envolvem de forma pró-ativa com a causa animal, informando-se e formando-se de maneira contínua para contribuir com ela.

\section{RELAÇÕES ENTRE ANIMAIS HUMANOS E NÃO-HUMANOS: UM BREVE CONTEXTO}

Quem são os animais não-humanos, e quais seriam as formas ética e legalmente corretas de nos relacionamos com eles, são questões cujas respostas

\footnotetext{
${ }^{2}$ Seres sencientes são aqueles que não apenas respondem a estímulos, mas possuem experiências mentais que acompanham os dados dos órgãos dos sentidos. No mínimo, os animais que possuem um sistema nervoso central ou similar são sencientes (DENIS, 2012).
} 
Atos de Pesquisa em Educação - ISSN 1809-0354

Blumenau, v. 10, n.2, p.654-680, mai./ago. 2015

DOI: http://dx.doi.org/10.7867/1809-0354.2015v10n2p654-680

têm sido buscadas de forma crescente por estudiosos de diversas áreas, indo da etologia e biologia (BALCOMBE, 2007; BEKOFF, 2007), até a filosofia (FELIPE, 2006; 2007; REGAN, 2006; SINGER, 1995; 2002) e o direito (CARDOZO DIAS, 2006; 2007; FRANCIONE, 2004; LEVAI, 2006).

No século $X X I$, essa crescente preocupação possivelmente esteja ligada ao fato de que as relações caracterizadas pela opressão dos humanos para com os outros animais superam numericamente de forma esmagadora aquelas que poderíamos considerar positivas, isto é, de respeito e/ou afeto. Em sua maioria, tais formas de opressão ocorrem de forma institucionalizada, visando atender a interesses de alguns setores da sociedade, sobretudo industriais.

Cinco grandes áreas da exploração animal representam uma parte significativa destas relações: a indústria da alimentação - que não se resume apenas à de carnes, mas também àquelas que utilizam seus derivados (como laticínios, ovos e mel); do vestuário (que inclui peles, couro, lã, seda); do entretenimento (circos, rodeios, touradas, rinhas, zoológicos, aquários, etc.); da criação de animais domésticos (pets); e as indústrias que se valem da experimentação animal, que são inúmeras (farmacêuticas, de produtos de limpeza, de higiene pessoal, de tintas e produtos químicos em geral, entre muitas outras). Vale ressaltar que a experimentação animal não se limita a usos industriais, mas é também realizada por instituições de ensino, de pesquisa e militares. Dentre essas formas de exploração, aquela que visa atender à indústria de alimentos é a que se utiliza do maior número de animais. Anualmente, cerca de 67 bilhões de animais terrestres são criados e abatidos no mundo para este fim (HSI, 2012) - o que equivale, em termos numéricos, a fazermos mil Segundas Guerras Mundiais por ano contra os animais.

A dimensão da violência expressa nesses números é difícil de apreender. A questão que está em pauta, porém, não é apenas a morte dos animais que quase sempre resulta dos diversos processos de exploração anteriormente citados, mas também as miseráveis condições de vida às quais eles são submetidos. $O$ sofrimento desses animais e a violação de seus direitos mais fundamentais (à vida, 
à liberdade e à integridade física e psicológica) têm sido amplamente descritos e documentados em textos e vídeos ${ }^{3}$.

O zoocídio que se configura nessas relações entre animais humanos e nãohumanos, e a intensidade dessa violência despertam, necessariamente, questionamentos éticos. Estes são pertinentes sobretudo quando percebemos que tal violência não é uma ideia com a qual as pessoas se sentem confortáveis contrariamente, a maior parte das pessoas, quando confrontadas com a realidade da opressão à qual os animais são submetidos nesses processos de exploração, demonstra tristeza, indignação e repúdio em relação às mesmas. A contradição entre nossas afirmações sobre o respeito que acreditamos ser devido aos animais não-humanos e a violência à qual estes são submetidos com a nossa participação (embora quase sempre de forma total ou parcialmente inconsciente, como consumidores alienados) resume a ideia à qual Francione (2004) tem se referido como nossa relação moralmente esquizofrênica com os animais. Ou seja, por um lado dizemos acreditar que os animais têm interesses moralmente significantes em não sofrer e, portanto, seria errado Ihes infligir sofrimento desnecessário. Por outro lado, a maioria do sofrimento e morte que lhes impomos não pode ser considerada necessária sob nenhum aspecto ${ }^{4}$.

Por que, então, essas práticas se perpetuam? Um dos prováveis motivos é que os processos de exploração animal acontecem de forma afastada do cotidiano da maior parte das pessoas, e a organização socioeconômica em torno delas preza para que assim seja (JOY, 2010). Esse ocultamento da violência praticada contra os animais, seguido da naturalização de nossa participação nos resultados dessa exploração, são parte da construção histórica de uma cultura de alienação em torno desses temas.

\footnotetext{
${ }^{3}$ Por exemplo, textos de Peter Singer, Gary Francione, Jonathan Safran Foer, João Epifânio Régis Lima, Sérgio Greif e Rob Laidlaw.; e os vídeos Terráqueos (2005), A testemunha (2000) e "Peaceable Kingdom" (2012), produzidos nos EUA; e A carne é fraca (2004), Não matarás (2006) e Vegana (2010), produzidos no Brasil.

${ }^{4}$ Tal contradição pode ser ilustrada pelo seguinte exemplo: em uma pesquisa da Humane Research Council, feita em 2008 nos EUA, cerca de $75 \%$ dos estadunidenses disseram que o país deveria eliminar todas as formas de crueldade e sofrimento animal (HERZOG, 2011). No entanto, o país é um dos maiores consumidores de carne do mundo, e esta é majoritariamente produzida em fazendas industriais, onde os animais são totalmente privados de seus direitos mais fundamentais.
} 
Atos de Pesquisa em Educação - ISSN 1809-0354

Blumenau, v. 10, n.2, p.654-680, mai./ago. 2015

DOI: http://dx.doi.org/10.7867/1809-0354.2015v10n2p654-680

Os abatedouros, fazendas de peles e laboratórios foram transferidos para locais afastados e/ou cercados de muros. No caso dos laboratórios, muitas vezes os animais vivisseccionados são previamente silenciados por meio de procedimentos cirúrgicos para que suas vocalizações de medo, dor e angústia não sejam ouvidas (LIMA, 2008). A carne no prato não se parece ao animal do qual ela provém, os produtos testados em animais não deixam transparecer a violência implícita em seu processo de fabricação, e os estilistas cada vez mais usam as peles disfarçadas em detalhes, de modo a criar uma sensação de que o luxo está mantido, mas não se parece ao animal do qual provém quando este estava vivo. Na indústria do entretenimento e de animais de companhia, a exploração e os maus-tratos são escondidos sob campanhas que os retratam como se estivessem se divertindo ao desempenharem seus papéis em circos e filmes, ou felizes em sadios lares estereotipados, sem mostrar a miséria à qual são submetidos nas condições de cativeiro, treinamento, criação e reprodução.

Dessa maneira as relações parecem amenas e são naturalizadas cotidianamente em cada ato de consumo de produtos provenientes da exploração animal, por meio dos códigos sociais e das campanhas de marketing das corporações envolvidas nesse setor (JOY, 2010; TIMMERMAN; OSTERTAG, 2011). O acesso a informações sobre os processos por trás dessas relações não é considerado um direito. Mais além, por vezes tais informações são consideradas agressivas e assim acabam sendo censuradas, sobretudo no que se refere à educação de crianças e jovens.

Tal cenário não deixa muito espaço para o questionamento e a reflexão crítica sobre esses processos, dando lugar à cultura de alienação. Conforme elucida Lima (2008), estar alienado significa pensar com ideias alheias, de acordo com a ideologia dominante e não com as ideias próprias que teríamos sobre um tema - o que nos torna alheios a nós mesmos. No caso da exploração animal, tal construção permite que os diversos interesses (que são sobretudo econômicos, mas não exclusivamente) que giram em torno dessas práticas se perpetuem.

As questões que se colocam então, visando diminuir e, idealmente suprimir a opressão exercida por parte dos humanos sobre os animais não-humanos, são: de que forma é possível romper esse processo de alienação? Como fazê-lo de modo a 
Atos de Pesquisa em Educação - ISSN 1809-0354

Blumenau, v. 10, n.2, p.654-680, mai./ago. 2015

DOl: http://dx.doi.org/10.7867/1809-0354.2015v10n2p654-680

sensibilizar as pessoas para o tema e, mais além, de modo a formar sujeitos animalistas? Qual o papel das IES nesse processo?

A busca de propostas sobre formas de contribuir para a formação de sujeitos animalistas, inclusive no contexto das IES, constituiu parte de um projeto de pesquisa de pós-doutorado mais amplo, que teve como objetivo analisar as interrelações entre a educação ambiental e o campo das relações entre animais humanos e não humanos. O método e os resultados parciais da pesquisa que enfoca o recorte do presente artigo serão apresentados nas próximas seções.

\section{AS FONTES E O MÉTODO DA PESQUISA}

A pesquisa contou com um estágio no exterior que gerou importantes aportes para os resultados aqui apresentados. Esta se valeu não apenas de revisão bibliográfica sobre o tema, mas também de fontes diretas de investigação.

Uma delas foi a participação e acompanhamento da disciplina Human-animal relations junto à Faculdade de Estudos Ambientais da Universidade de York em Toronto (ON, Canadá). A disciplina está voltada a uma revisão crítica das relações entre animais humanos e não humanos, e seu acompanhamento foi feito com uma intenção investigativa, incluindo a realização de um survey ${ }^{5}$ com os estudantes ao final do curso, visando obter suas percepções sobre o mesmo.

A segunda fonte direta de pesquisa foi a realização de dez entrevistas com pessoas ligadas à questão animal, sendo duas nos EUA e oito no Canadá, com pessoas tanto do meio acadêmico, quanto ligadas a ONGs ou com trabalhos independentes relacionados ao tema. Dentre os entrevistados, cinco são docentes em universidades (uma universidade nos EUA e três no Canadá, sendo que duas docentes entrevistadas pertenciam à mesma universidade).

\footnotetext{
${ }^{5}$ Um survey refere-se à obtenção de informações sobre características, comportamento ou opiniões de um determinado grupo, que representa uma certa população alvo, por meio de algum instrumento de pesquisa (FREITAS et al. 2000). Neste caso, tal instrumento consistiu num questionário, que foi aplicado de forma anônima aos participantes do curso, com algumas questões abertas e outras fechadas.
} 
Atos de Pesquisa em Educação - ISSN 1809-0354

Blumenau, v. 10, n.2, p.654-680, mai./ago. 2015

DOl: http://dx.doi.org/10.7867/1809-0354.2015v10n2p654-680

As entrevistas foram compostas de perguntas abertas, e abordaram questões referentes à formação formal e não formal de pessoas comprometidas com uma ética de respeito aos animais não humanos (incluindo a própria história pessoal dos entrevistados); ao ativismo pela causa; e aos conceitos e métodos sugeridos e/ou já utilizados pelos entrevistados nesses campos de atuação.

Questões especificamente relacionadas aos conceitos e métodos utilizados em aulas sobre a questão animal, bem como sobre o contexto institucional para inserção do tema em IES, foram direcionadas prioritariamente aos cinco docentes entrevistados. A análise das entrevistas foi feita de forma qualitativa.

\section{DA EMPATIA INATA À FORMAÇÃO DE SUJEITOS ANIMALISTAS: O 'PONTO DE VIRADA ${ }^{, 6}$}

Nas questões relacionadas às histórias de vida dos entrevistados, o primeiro elemento que se destaca é que oito entre dez deles apontaram o fato de terem tido uma forte empatia e conexão com os animais durante a infância, fossem eles cães ou gatos, 'animais de fazenda'7 (vacas, porcos, galinhas, etc.), ou mesmo animais com os quais tiveram breves contatos em zoológicos, circos ou aquários. Algumas passagens ilustram esses sentimentos ${ }^{8}$ :

Suj. A: "Sempre fui muito curiosa em relação aos animais, desde muito pequena [...]. Eu gostava de ir ao quintal e pegar animais apenas para olhálos, e depois deixá-los seguir. Naquela fase, tinha muito a ver com o encantamento, com o fato de eu ficar maravilhada com eles. Eu gostava de brincar, por exemplo, com cobras e sapos - meus pais ficavam desapontados porque eu não tinha interesse em brincar com bonecas [...]. Eu sempre estive tão enamorada...apaixonada, realmente, por essa diversidade de animais,

\footnotetext{
${ }^{6}$ As aspas simples neste subtítulo referem-se à tradução livre da expressão "Turning point", utilizada por um dos entrevistados para designar o momento em que ele compreendeu algumas questões importantes relacionadas à posição político-ideológica do abolicionismo animal, gerando uma mudança paradigmática e pragmática em seu modo de vida.

${ }^{7}$ Nenhum animal é, por natureza, de fazenda. Essa é uma designação construída e normalizada pela moralidade especista predominante, que categoriza os outros animais segundos a utilidade que lhes destina para os humanos - 'de fazenda', 'de estimação', 'de laboratório', e assim por diante. Por isso essa expressão foi colocada também entre aspas simples.

${ }^{8} \mathrm{~A}$ transcrição e tradução de todas as entrevistas apresentadas no artigo foram feitas pelos autores.
} 
essas possibilidades. A vivacidade, a vida, sempre foi algo extraordinário para mim."

Suj. B: "Eu cresci no campo, a primeira fazenda onde morei tinha vacas, porcos, galinhas, cães e gatos; a segunda criava gado para corte e porcos. Então eu estava muito conectada aos outros animais, passava muito tempo com eles, brincando com gatos, alimentando o gado, e coisas assim, e para mim tornou-se muito claro que eu tinha uma forma diferente de perceber e me aproximar dos animais do que todas as demais pessoas na minha família e na

minha comunidade. Eu não gostava de cortar as cabeças dos frangos, ou de castrar os porcos, essas coisas sempre me causavam ansiedade, e a forma como a minha familia olhava para isso era dizendo que eu era muito impressionável e tinha medo de sangue - o que não era verdade, mas acho que era pelo fato de que eu era tão estranha para eles, e eles não conseguiam compreender por quê eu sentia essa compaixão e me conectava com aqueles animais como pessoas."

Suj. C: "Acho que sempre tive uma conexão muito forte com os animais, desde pequena - desde o gato que eu tinha em casa, com quem tinha uma relação muito forte, até o fato de que eu me recusava a ir a zoológicos ou circos. Então de alguma forma eu tinha algum tipo de consciência sobre essa questão animal desde pequena, eu achava que os animais em zoológicos ou circos pareciam tristes. Eu me identificava com eles, tinha alguma noção de que eles não queriam estar ali."

Nessas passagens observa-se a existência de um sentimento de identificação com os animais que, segundo Fudge (2002), é inato à maioria dos seres humanos, porém tende a ser gradativamente enfraquecido ao longo da vida por meio dos códigos sociais que naturalizam as relações de opressão entre humanos e os outros animais e infantilizam, de forma pejorativa, a sensibilidade em relação a estes últimos. Um indicativo do que viriam a ser esses códigos sociais na vida adulta, dentro de círculos sociais mais expandidos, já pode ser observado nas falas das entrevistadas A e B, quando relatam a forma como o ambiente familiar e comunitário recebia a sua empatia para com os animais quando elas eram crianças.

A forte influência desses processos de naturalização da exploração animal por parte da sociedade faz com que a conexão com os outros animais na infância não garanta, necessariamente, a formação de adultos atentos e orientados a intervir pelas questões animais. Outros estímulos posteriores, tanto sensitivos quanto racionais, mostraram-se fundamentais nessas trajetórias. 
Novamente em oito das dez entrevistas realizadas, observou-se a existência de um 'ponto de virada', isto é, um estímulo mais forte dentro de algum processo que estava em curso ou iminente, que impulsionou o desvelamento de questões importantes sobre as formas como nos relacionamos com os outros animais e a desconstrução dos processos de naturalização dessas relações, reascendendo, na vida adulta, a conexão com eles. Na experiência dos entrevistados, isso ocorreu pelo contato com filmes, livros, movimentos sociais ou contextos acadêmicos, isoladamente ou de forma conjugada, que de alguma maneira sensibilizaram e/ou informaram sobre questões referentes à exploração de animais ${ }^{9}$.

Em todos os casos, esses estímulos levaram à busca de mais informações com um olhar crítico, desencadeando um processo de auto-formação permanente que definimos, no presente artigo, como característica dos sujeitos animalistas.

Os processos de reconexão desencadeados a partir dessas experiências podem ser ilustrados em algumas falas:

Suj. D: "Eu cresci comendo carne, mas esse era um tema sobre o qual eu nunca havia pensado, e as imagens que eles (ativistas em protesto de rua) me mostraram eram emocionalmente muito difíceis de processar, e chocantes, porque eu havia crescido com aquela noção de que todos os animais de produção eram bem tratados. [...] Fiquei triste e horrorizada com o tratamento dado aos animais, e me tornei vegana ${ }^{10}$ praticamente de imediato, de um dia para o outro, porque eu não queria participar de um sistema de exploração como esse [...]. Isso se tornou uma parte importante da minha identidade."

Suj. E: "Fiquei tão impressionado (com o livro 'All that dwell therein', de Tom Regan) que tirei cópias e comecei a carregar o livro comigo e mostrá-lo às pessoas, e a dar as cópias de presente. O livro apresentava os argumentos

\footnotetext{
${ }^{9}$ Exemplos dos estímulos que foram citados como responsáveis pelo início dessa reconexão foram: o livro 'All that dwell therein', de Tom Regan; um vídeo sobre vivissecção exibido em evento organizado em uma universidade por grupos punk, onde havia bandas pró-feministas, anti-homofóbicas e veganas; um protesto de rua organizado por ativistas ligados à PETA (People for the Ethical Treatment of Animals) em frente a uma loja de uma das grandes redes de fast food do mundo; o encontro com um ambiente acadêmico onde a questão animal já começava a ser abordada e onde havia algumas pessoas vegetarianas e veganas; o livro 'The sexual politics of meat', de Carol Adams; o documentário 'The animal's film', apresentado em 1979 no Toronto Festival of Festivals e um dos primeiros filmes produzidos no mundo mostrando a realidade da exploração animal na produção de alimentos, no entretenimento, em pesquisas e testes de laboratório.

${ }^{10}$ Veganos são pessoas que elegem como conduta ética a eliminação de qualquer prática que implique a morte ou exploração de animais, seja na alimentação, vestuário, produtos de higiene pessoal, limpeza, cosméticos, ou no entretenimento (BLUWOL, 2010).
} 
pelos quais eu até então não havia passado, mas que me pareceram muito lógicos. Esse foi o meu ponto de virada pessoal, onde eu passei de ser uma pessoa vagamente ciente sobre o movimento dos direitos animais, para me tornar eu mesmo uma pessoa dos direitos animais."

Suj. B: "A experiência em (nome da universidade) foi transformadora para mim, lá eu descobri que existia uma linguagem para descrever como eu me sentia, e que havia outras pessoas que se sentiam assim [...]. Naquele ambiente eu estava rodeada de pessoas que eram vegetarianas, ou veganas - e eu nunca havia ouvido a palavra vegan antes. [...] Isso foi no início dos anos 90. Então foi maravilhoso, aprendi a palavra 'antropocentrismo', e isso foi fantástico, porque finalmente eu encontrava uma linguagem para descrever sentimentos que eu tinha, e percebi que esses sentimentos chamavam-se 'empatia'! Isso me ajudou muito, e a partir daí eu percebi que podia fazer trabalho acadêmico nesse campo, e isso me levou a começar a olhar para os aspectos educacionais da nossa relação com os animais; como construímos isso com os animais."

Nessas falas, percebe-se que em alguns casos os estímulos foram de caráter mais emocional, e em outros mais racionais, porém sempre acabavam por se complementar mutuamente. Nesse sentido, a formação pessoal e formal (acadêmica) dos entrevistados - nos casos em que esta existe - se conectam e potencializam, e assim não apenas eles mesclam o ativismo pela causa animal a uma atuação profissional na área, mas também o fato de essas pessoas serem sujeitos animalistas torna-se um fator muito importante de suas identidades. Posicionar-se contra a exploração animal implica em ter um olhar crítico para com o mundo, não se permitir ficar alienado, e posicionar-se também contra várias outras formas de exploração e opressão. A esse respeito, uma docente da área de Estudos Críticos Animais (ECA) explica:

Suj. C: "Os ECA incorporam um certo tipo de análise que me interessa - olhar para a interseccionalidade, relacionar ambientalismo e teorias feministas, do trabalho, de raça, de homossexualidade, pós-colonialismo; críticas ao capitalismo e à economia [...]. Interessa-me a compreensão da inter-relação entre esses diferentes pontos e entre a academia e o ativismo (uma área deve informar, alimentar a outra e vice-versa, numa abordagem dialógica), ou seja, deve ser contra uma análise isolada das questões animais, entendendo que quando falamos de opressão animal devemos entender que ela se relaciona com outras formas de opressão." 
A fala de outra entrevistada traz essas conexões entre diferentes formas de opressão dentro de sua experiência pessoal:

Suj. A: "Eu me tornei vegetariana muito nova, tinha por volta de dez anos para desconcerto dos meus pais. Eu era muito consciente sobre a violência. Cresci em uma casa bastante violenta, então tenho certeza de que aprendi isso muito cedo, e eu não queria participar de nenhum tipo de violência contra nenhum ser vivo."

Entretanto, provocar esse ponto de virada, essa reconexão com a sensibilidade para com os outros animais, e a compreensão das inter-relações entre diferentes formas de opressão não é trivial ${ }^{11}$.

Uma primeira dificuldade é que o tema provoca um enfrentamento das pessoas com questões de extrema violência com as quais em geral elas não estão emocionalmente preparadas para lidar, causando muitas vezes sensações de choque, desamparo e impotência. Além disso, usualmente elas não desejam compactuar com esta realidade, porém todo o ambiente social que nos circunda tende a naturalizar nossa inserção nesses processos de exploração animal, dificultando assim a visualização de uma possibilidade de ruptura com o mesmo, sendo este um segundo motivo de desconforto. Ao tocar temas cujos reflexos afetam as decisões cotidianas e consideradas pessoais de cada um - tais como a forma de se alimentar, vestir, escolher produtos de higiene, etc. - somado ao desconforto provocado pelo tema em si, algumas pessoas reagem agressivamente, outras não querem sequer tomar contato com essa realidade e procuram se esquivar de informações e estímulos sobre o tema. Por fim, o movimento pelos direitos animais é diverso, uma vez que não há respostas fáceis para muitas das questões éticas que emergem nesse âmbito, o que pode gerar inseguranças àqueles que se propõem a se envolver com a causa.

A sistematização de conteúdos e métodos que sejam capazes de criar um ambiente favorável a um questionamento e posicionamento crítico sobre o tema é,

\footnotetext{
${ }^{11}$ Os desafios que serão apresentados nesse sentido não apenas são explicitados por autores como DeMello (2010) e Engel Jr. e Jenni (2010), mas também foram vivenciados pelos autores deste artigo durante curso de extensão realizado em universidade pública brasileira, voltado a olhar criticamente para questões referentes à exploração animal.
} 
portanto, um grande desafio. A seguir apontamos algumas possibilidades levantadas a partir da pesquisa realizada, enfocando as potencialidades de se abordar o tema no contexto de IES.

\section{ELEMENTOS DE CONTEÚDO E MÉTODO PARA A FORMAÇÃO DE SUJEITOS ANIMALISTAS}

No que se refere à organização de conteúdos e métodos para um programa de formação nesse campo, uma das questões que se mostrou positiva ao longo da pesquisa foi a de se iniciar pelo reencantamento das pessoas em relação aos outros animais, provocando a busca da curiosidade e da admiração que provavelmente existiram em alguma fase da infância de cada um.

Esse processo envolve levantar questões sobre quem são os animais nãohumanos, abordando aspectos de sua vida emocional, sociabilidade, subjetividade, inteligência, linguagem, sua capacidade de sentir dor física e psicológica, bem como de buscar prazer e diversão. A ciência tem gerado crescente conhecimento sobre esses temas, havendo hoje uma vasta quantidade de materiais disponíveis ${ }^{12}$.

É fundamental, ainda, provocar reflexão sobre as formas como nós, humanos, interpretamos essas informações, pois é essa reflexão que pode nos levar a uma reinterpretação de nossas relações com os outros animais. Acessar essas questões a partir de um olhar não antropocêntrico nos permite enriquecer o apreço por eles, transformando a percepção deles como coisas, ou criaturas simplesmente instintivas, para a de sujeitos que pensam e sentem. Segundo um dos entrevistados, a partir dessa perspectiva, pode-se ajudar a criar a compreensão de que: "os animais têm uma biografia, não simplesmente uma biologia. Eles têm vidas que importam para eles mesmos".

Nessa etapa de reencantamento, algumas estratégias de aproximação com os animais podem ser incentivadas de forma complementar. Nesse sentido, uma das docentes entrevistadas comenta sobre atividade que propõe em sua disciplina:

\footnotetext{
${ }^{12}$ Ver, por exemplo, Balcombe (2007); Bekoff (2007); Fawcett (2012); Fudge (2002); Pepperberg (2008).
} 
Suj. A: "Uma das minhas grandes preocupações é que há muita romantização no movimento animal e na defesa animal, e eu sinto que às vezes os animais mesmo ficam perdidos, generalizados, usados. Então eu gosto de começar com animais específicos sobre os quais os estudantes podem aprender. Normalmente eu gosto de fazer aulas ao ar livre, onde eles têm que escolher um animal e segui-lo, e fazer anotações, consecutivamente, de modo que eles prestem atenção no que aquele ser está fazendo, como ele está vivendo. Cada vez mais, eu quero que eles tenham uma noção disso antes de entrar na questão do complexo industrial que envolve os animais, dos direitos animais, do bem-estar animal, uso de animais na experimentação e tudo isso. Eu quero que eles tenham a percepção de uma vida vivida por um animal, e que tenham a habilidade de observar isso, porque acho que essa é uma capacidade que tem diminuído. Em parte, quero que eles vejam a interconectividade e interdependência. E no final (da disciplina), quero que eles tenham as ferramentas para seguir o fio da defesa animal, através das diferentes teorias sobre as quais conversamos."

Ao provocar a imersão de cada pessoa no universo de vida de um animal específico, esse tipo de experiência pode ajudar a romper a distância colocada pelas categorias usualmente utilizadas para definir espécies - que são muito amplas e genéricas para apreender a singularidade não apenas de cada espécie, mas de cada animal individualmente (DERRIDA, 2002) - aproximando as pessoas à percepção da subjetividade e individualidade de cada animal.

A complementaridade entre a sensibilização e o acesso a informações, com a possibilidade de reflexão sobre a natureza de cada animal, tende a facilitar a abertura para o tema complexo e difícil que se propõe abordar na sequência.

A etapa seguinte da formação consistiria em revelar o contexto do problema tratado, isto é, qual é a realidade que as pessoas ligadas à causa animal estão procurando enfrentar. Isto implicaria em contextualizar as construções históricas sobre as categorias, usos e relações com os animais, e as formas como estas influenciaram o entendimento que temos hoje sobre eles. Deveria mostrar, ainda, de quais formas os animais são explorados, por que essa é uma importante questão de justiça social, como ela se conecta com outras formas de violência e opressão, e quais são a lógica e o sistema que sustentam a exploração animal, contextualizando assim os fatores que levaram ao surgimento dos movimentos pelos direitos animais.

Nessa etapa, seria importante apresentar os principais argumentos das teorias voltadas aos direitos animais, bem como as diferentes correntes e 
movimentos existentes dentro da causa ${ }^{13}$, permitindo à pessoa em formação que as compreenda e se posicione nesse contexto.

Além da teoria, questões práticas abordando a legislação e a criação de órgãos competentes para atendê-la, problemas reais existentes em contextos locais, políticas públicas voltadas ao tema, atuação de ONGs, ativismo, e de que forma essas questões se refletem no cotidiano da vida dos animais e nas nossas próprias vidas são fundamentais para tornar o tema mais palpável e facilitar a compreensão de como essas questões se relacionam.

Dialogar a respeito de formas de intervir no mundo de modo positivo no que se refere aos temas estudados também tem se mostrado essencial nesses processos de formação, sobretudo considerando-se o impacto que é usualmente gerado nas pessoas pela apresentação das questões sobre exploração animal. Tais intervenções podem se dar de formas muito diversas, desde o envolvimento com movimentos sociais, políticas públicas e ativismo; com atividades de formação e comunicação; até mudanças de hábitos e de posicionamento político em relação ao tema. O envolvimento em qualquer destas iniciativas, ou em uma combinação de várias delas, permite à pessoa em formação assumir uma postura pró-ativa em relação à causa, o que contribui para superar o sentimento de impotência frequentemente gerado pelo contato com o tema.

Considerando especificamente a possibilidade de uma formação realizada em IES, a própria avaliação pode incluir a demanda de que os estudantes realizem alguma intervenção real e fundamentada pelos animais. Tal proposta foi feita na disciplina acompanhada junto à York University, e a título de exemplo destacamos aqui uma das intervenções, onde um grupo de estudantes optou por fazer uma demanda formal ao Departamento de Biologia da Universidade - no qual eles eram discentes - pelo fim da prática de vivissecção nas atividades de ensino e pesquisa nesse departamento. Isso implicou a realização de um levantamento aprofundado sobre os argumentos éticos e científicos que embasam essa proposta, bem como de informações sobre os métodos alternativos existentes no mercado, seu preço e

\footnotetext{
${ }^{13}$ Por exemplo, Brügger (2009); Naconecy (2009); Francione e Garner (2010), sobre as diferenças entre abolicionismo e bem-estarismo; Singer (2002); Regan (2006) e Francione (2004) sobre direitos animais, e Donovan (2006) sobre a ética do cuidado.
} 
disponibilidade; até formas de mobilizar a comunidade universitária para apoiar a proposta e encontrar os caminhos institucionais para apresentá-la e fazê-la chegar às instâncias decisórias da universidade para avaliação.

Além de contribuir para superar o sentimento de impotência, esse tipo de intervenção permite aos estudantes o aprofundamento em algum tema específico de seu interesse, e a reflexão sobre responsabilidades individuais e coletivas para com os outros animais. Permite, ainda, um ganho de percepção sobre as potencialidades e os tipos de obstáculos reais que precisam ser enfrentados para se realizar algo concreto pela causa.

No que se refere a minimizar os impactos negativos que podem ser gerados pela apresentação do tema, outras questões metodológicas interessantes emergiram durante a pesquisa. A primeira delas é que deve-se procurar criar um ambiente onde os participantes se conheçam pessoalmente e haja confiança entre eles em sua complexidade como seres humanos, buscando minimizar as chances de que ao longo do curso diferentes grupos passem a ver uns aos outros sob posições estereotipadas e simplificadas, tais como 'defensores de animais' ou 'exploradores de animais', 'carnívoros' ou 'vegetarianos/veganos', etc.

A criação de confiança é importante também porque os temas a serem apresentados, além de eticamente complexos são emocionalmente difíceis, e assim falar e posicionar-se a respeito deles será mais fácil se as pessoas se sentirem acolhidas pelo ambiente onde estão.

Produzir e compartilhar com os colegas textos autobiográficos, incluindo experiências significativas (boas e más) vividas com animais; bem como a realização de viagens de campo, foram citadas pelos entrevistados como atividades que contribuem fortemente para criar laços entre os participantes, produzindo um ambiente acolhedor onde os diferentes pontos de vista possam ser explicitados.

Todos os docentes entrevistados, bem como autores que abordam o tema na literatura (POTTS; ARMSTRONG, 2010; PORTER, 2010; MONTGOMERY; KALOF, 2010; ENGEL JR.; JENNI, 2010), enfatizam a importância de se utilizar uma pedagogia crítica e ativa. Propiciar espaço para discussões em grupos e questionamentos sobre as ideias apresentadas, proposição de temas e atividades de interesse para os participantes da formação, e contato com membros da 
comunidade que estejam envolvidos em alguma atividade relacionada às questões em pauta foram alguns dos pontos destacados nesse sentido.

Em coerência com isso, no que se refere às relações entre os participantes e o docente, ressaltou-se que é fundamental que este último assuma uma postura aberta e dialógica em relação ao tema, não permitindo a compreensão de que determinado ponto de vista esteja sendo imposto ${ }^{14}$. Ao invés de ser possivelmente compreendida como uma afronta ou acusação, a postura do docente deve ser vista como um convite solidário a olhar criticamente para um tema complexo ${ }^{15}$.

No que concerne aos materiais utilizados ao longo da formação, todos os docentes entrevistados disseram utilizar textos que tragam diferentes perspectivas sobre os temas tratados para embasar os diálogos. Estes são combinados com outros recursos em aula, tais como fotos, vídeos e entrevistas com pessoas atuantes na área, de modo a dar suporte a algum argumento ou a tornar o tema mais vivo.

O uso de vídeos e filmes, particularmente, é enfatizado por vários autores (POTTS; ARMSTRONG, 2010; PORTER, 2010; MONTGOMERY; KALOF, 2010), uma vez que os animais não-humanos e suas relações com os humanos podem ser representados de forma mais realista, imediata e vívida nas telas.

A fala de uma docente sintetiza algumas das questões apontadas acima: a importância da complementaridade entre o sensível e o racional na formação, a questão da empatia e dialogicidade entre docentes e demais participantes, e a importância do uso de diversos recursos, tais como imagens e vídeos:

Suj. C: "Eu uso imagens visuais, porque para mim elas foram tão poderosas, e vejo nas minhas aulas que elas têm um efeito poderoso para outras pessoas também. Acho que não há problema em que alguns estudantes tenham reações fortes a essas imagens, tive estudantes que choraram nas aulas - e tento prepará-los para isso, eu digo que sei que é muito difícil olhar para aquilo, que também é difícil para mim, mas que eu acho que é uma questão importante para a qual devemos dar atenção. As imagens nos auxiliam a pensar porquê aquilo está acontecendo. Eu não os bombardeio com vídeos, assistimos 15 ou 20 minutos e aí vamos para a discussão. Em geral é aí que eu vejo que começa uma transformação, as pessoas viram algo

\footnotetext{
${ }^{14}$ Para abordagens de uma pedagogia dialógica, ver Buber (1979) e Freire (1983).

${ }^{15}$ Esta postura por parte da docente, e o estímulo à reflexão crítica, foram destacados como alguns dos pontos mais positivos na avaliação feita junto aos estudantes da disciplina Human-animal relations.
} 
que lhes causou um impacto emocional e...eu acho que as pessoas se importam, elas só não tiveram a oportunidade de pensar naquilo. Por isso eu não quero que seja uma abordagem somente intelectual, eu quero que seja também uma forma emocional de aprender, e para ser coerente com isso, nós experienciamos emoções referentes ao sofrimento animal e esse é um bom ponto de partida para a discussão."

\section{INSTITUCIONALIZAÇÃO}

Neste tópico apresentamos brevemente algumas considerações quanto à possibilidade de institucionalização da formação sobre os Estudos Críticos Animais, com base nas experiências acadêmicas visitadas na América do Norte.

A primeira e mais específica delas refere-se a uma universidade situada nos EUA, criada e mantida por uma grande ONG internacional de defesa dos direitos animais. Essa universidade possui cursos de graduação e pós-graduação que enfocam a formação de estudantes para atuarem em diversas áreas voltadas à questão animal, tais como proteção, políticas públicas, advocacia (defesa), educação e gerenciamento de organizações sem fins lucrativos que atuam nesse campo. Apresenta também um programa de educação continuada, para profissionais que já atuam nas áreas de movimentos sociais humanitários, educação humanitária e fiscalização. Esses cursos ainda estão passando pelo que seria semelhante, no Brasil, a uma certificação do Ministério da Educação. Ainda assim, segundo docente dessa universidade, as pessoas formadas por ela têm encontrado boa aceitação no mercado de trabalho.

Essa universidade não conta com nenhum apoio governamental, sendo sustentada em parte pela verba que os estudantes pagam. Entretanto, com cento e vinte estudantes em 2013, ela ainda não era autossuficiente nesse sentido, sendo esse um objetivo que a instituição busca alcançar. Os demais custos são complementados pela ONG, à qual a universidade se vincula, sendo que esta, por sua vez, tampouco tem nenhum apoio oficial, dependendo totalmente de doações para manter suas atividades.

Em termos de amplitude do programa, diversidade e expertise dos docentes, e acúmulo de experiência institucional na área, esta universidade está muito bem preparada para oferecer uma formação específica sobre questões animais. Por 
outro lado, a falta de maiores recursos financeiros cria algumas limitações; como por exemplo, o fato de que a maior parte dos cursos sejam à distância ou semipresenciais $^{16}$, ou que a universidade não tenha ainda condições de contratar os docentes para fazerem pesquisa, de modo que a maioria trabalha na instituição em tempo parcial.

Mesmo enfrentando algumas dificuldades - sobretudo de ordem financeira - a maior maturidade do tema e a existência de ONGs com grande capacidade de captação de recursos em países como EUA e Canadá viabiliza a existência de uma universidade com essa lógica de funcionamento nesses países, o que acreditamos ser ainda difícil no contexto brasileiro. Ainda assim, essa experiência traz ideias interessantes que podem ser adaptadas, por exemplo, para cursos de especialização no Brasil.

Já os demais casos vistos ao longo da pesquisa são de três universidades canadenses - às quais vamos nos referir aqui como $A, B$ e $C$ - com contextos mais próximos aos das universidades públicas brasileiras.

$\mathrm{Na}$ universidade $\mathrm{A}$, a questão animal vem sendo inserida aos poucos em algumas disciplinas, por duas docentes que têm interesse na área, porém não há ainda matérias específicas que tratem exclusivamente dessas questões. O tema é abordado pelas docentes em disciplinas de graduação e pós-graduação voltadas à educação ambiental, pedagogias críticas, estudos de gênero e educação para justiça social (sendo que nesta última é utilizada uma abordagem interseccional entre questões voltadas aos animais, ao feminismo, ao homossexualismo e ao racismo, entre outras). Dessa forma, diversos estudantes a cada ano acabam tendo contato com a questão, e alguns terminam por se aprofundar no tema em trabalhos de pós-graduação orientados pelas docentes. Apesar desse contexto existente, o tema ainda não está de fato institucionalizado dentro dessa universidade, pois depende muito da presença e persistência das docentes comprometidas com a

\footnotetext{
${ }^{16} \mathrm{Com}$ isto não pretendemos desmerecer a importância da educação à distância, que em muitos aspectos apresenta vantagens em relação à presencial - por exemplo, em sua capacidade de atender um público diverso em diferentes lugares do país - porém acreditamos que a possibilidade de ter também cursos inteiramente presenciais seria interessante.
} 
causa para que seja abordado dentro de disciplinas que não foram inicialmente designadas especificamente para tratar desse tema ${ }^{17}$.

No caso da universidade $B$, existe hoje uma disciplina específica voltada ao tema de relações humanos-animais, porém sua aceitação não foi imediata. Inicialmente, alguns docentes utilizaram-se da mesma estratégia citada no exemplo anterior, isto é, inserir conteúdos sobre as relações humanos-animais em disciplinas que tinham abordagens correlacionadas, tais como história natural, educação ambiental, ecofeminismo, pensamento crítico e justiça socioambiental, para depois chegar à criação da disciplina propriamente dita. A esse respeito, a docente responsável colocou:

Suj. A: "Eu tive que lutar para que essa disciplina fosse aceita na universidade. [...] Não havia nenhuma cadeira com esse perfil; [...] a maior parte das disciplinas que tinham alguma aproximação com animais os viam como espécies ou como símbolos, e não como sujeitos de suas vidas. [...] tive que passar por todos os níveis da burocracia para aprová-la aqui. Tive alguns questionamentos, vindos da Biologia, das ciências, um pouco das artes...do tipo, eu estava falando de animais como sujeitos? Porque eu disse que ia ser um curso pós-cartesiano, eu havia dito também que ia falar sobre direitos, então houve uma certa oposição por parte da administração. Mas é uma universidade grande!"

O trecho transcrito ilustra parte das dificuldades enfrentadas para se legitimar uma disciplina cujos princípios escapam à tradição da universidade em questão, propondo algumas mudanças paradigmáticas tais como 'falar de animais como sujeitos'.

Por outro lado, é fato que vem se criando abertura de forma crescente nas universidades, sendo que um elemento que a favorece é o expressivo interesse dos estudantes pelo tema. Em ambos os casos (universidades A e B), as docentes também realizam trabalho de pesquisa e orientação em estudos críticos animais e temas correlatos, e há igualmente um interesse significativo por parte de estudantes

\footnotetext{
${ }^{17}$ Por ser um tema que demanda uma abordagem interdisciplinar, o fato dos ECA serem inseridos em outras disciplinas de forma transversal não é visto como algo negativo per se. Apenas consideramos assim quando o tema fica relegado a outras disciplinas por falta de espaço e legitimidade institucional, tendo os docentes como única opção abordá-lo dessa forma.
} 
de pós-graduação ${ }^{18}$. As entrevistas com as três docentes dessas duas universidades denotam que há uma expectativa de que o tema, e sua institucionalização, continuem a se ampliar nessas universidades.

Por fim, a experiência da Universidade C é a mais avançada, em termos de institucionalização, entre as três universidades canadenses analisadas durante a pesquisa. Partindo de processos similares aos descritos para A e B - isto é, de docentes comprometidos com a causa inserindo o tema gradativamente na formação de estudantes de graduação e pós-graduação - a universidade $C$ criou, em 2007, uma área de concentração em Estudos Críticos Animais dentro de seu Departamento de Sociologia, sendo a primeira universidade do Canadá a oferecer essa formação.

O objetivo dessa concentração é questionar ideias pré-concebidas que temos sobre nossas relações com outros animais e os papéis que eles desempenham em nossas vidas, as diferentes formas como tratamos animais de espécies diferentes, e a distinção que fazemos entre as sociedades humanas e as de outros animais. Suas disciplinas abordam a subjetividade animal, o status legal dos animais, as formas como os animais são retratados em diferentes culturas, as relações entre humanos e animais, a teoria e o movimento de libertação animal e estes em conversação com as teorias feminista, do trabalho, teoria crítica de raças, e teorias ambientais.

Em termos de institucionalização, o fato de a concentração em ECA ser abrigada por um curso de sociologia que tem tradição em questões de justiça social foi determinante para que houvesse abertura para sua criação, bem como para uma aceitação mais natural do tema pelos estudantes. Uma docente dessa universidade comenta:

Suj. C: "Há um contexto cultural diferente aqui neste campus; porque os ECA aqui compõem um campo de estudos legítimo. Muitos estudantes vêm do curso de sociologia onde a discussão dos movimentos anti-opressão é um tema importante; no departamento há muitos professores falando sobre

\footnotetext{
${ }^{18}$ Tal interesse pôde ser observado por meio de questionário aplicado junto aos estudantes da disciplina de Human-animal relations oferecida na universidade de York em 2013. A disciplina não é obrigatória para nenhum curso, e teve suas vagas totalmente preenchidas por estudantes vindos das mais diversas áreas, que a avaliaram como interativa e estimulante, com aulas e leituras interessantes que provocavam reflexão. Informações trazidas por DeMello (2010) e Potts e Armstrong (2010) corroboram esse crescente interesse dos estudantes pelo tema na América do Norte.
} 
feminismo, sobre questões de trabalho, sobre temas difíceis, relacionados à equidade, questões sobre dor, sofrimento e opressão num contexto humano, então eles chegam aos estudos sobre animais sabendo que o terreno aqui é de uma sociologia crítica, e que o viés é o da anti-opressão. Então acho que a questão animal é de alguma forma um próximo passo para eles refletirem."

Somado à tradição do departamento de sociologia dessa universidade, houve um contexto mais amplo que também foi favorável, uma vez que docentes de outros departamentos - ciência política, artes, psicologia e inglês - também passaram a abordar temas relacionados aos ECA dentro das suas próprias disciplinas. Estes docentes criaram um grupo de trabalho visando atuar de forma complementar, o que também amplia o tema junto aos discentes, uma vez que estudantes de diversos departamentos vão até a sociologia fazer disciplinas relacionadas aos ECA, bem como estudantes da sociologia vão fazer disciplinas que dialogam com esse tema em outros departamentos.

Assim, criou-se nessa universidade uma legitimidade em torno do tema, que se dá não apenas pela institucionalização das diversas disciplinas que abordam os $E C A$, mas sobretudo pelo contexto sociocultural que permitiu que isso ocorresse.

Tal contexto amplia a capacidade de institucionalização e o alcance do tema. No caso em questão, por exemplo, foi criado um novo instituto de justiça social na universidade, e parte dele (e dos recursos nele alocados) será voltado para justiça animal. Isso confere novas possibilidades de atuação em docência, pesquisa e extensão, reforçando a capacidade da universidade de investir de forma crescente nesse tema.

\section{CONSIDERAÇÕES FINAIS}

A formação de sujeitos animalistas é uma questão nova porém muito pertinente no mundo contemporâneo, e apresenta alguns desafios concretos. Embora a formação formal não seja o único caminho, as IES têm enorme potencial para contribuir nesse processo.

A partir da pesquisa realizada, duas questões destacaram-se nesse sentido: os desafios da formação em si, no que concerne a seus objetivos, conteúdos e métodos, e aqueles referentes à abertura de espaço para sua institucionalização nas 
IES, como um campo legítimo de conhecimento a ser incluído na missão da universidade, nos campo do ensino, pesquisa e extensão.

No que se refere ao primeiro desafio apontado, o tema demanda uma abordagem crítica e dialógica que considere questões éticas, científicas e culturais sobre as formas de nos relacionarmos com os animais, e que seja capaz de fazer o grupo de estudantes e docentes transitarem entre a teoria e a prática, dentro e fora da sala de aula, afetando tanto a formação acadêmica quanto pessoal dos envolvidos. Deve, ainda, fomentar a produção de novos conhecimentos e formas de pensar pelo grupo, a partir da análise crítica das questões que envolvem as relações entre animais humanos e não-humanos.

Quanto ao processo de institucionalização do tema em IES, nos exemplos apresentados, observam-se dois caminhos diferentes: o primeiro é o de uma grande organização voltada à causa animal, que cria uma universidade para difundir o tema e preparar pessoas para atuarem nele; e o segundo é o do tema sendo inserido gradativamente em universidades 'tradicionais', onde vai rompendo barreiras e paradigmas até ganhar legitimidade. Este ganho de legitimidade pode ocorrer por meio de um círculo virtuoso, onde sua inserção como tema de disciplinas e/ou pesquisa, inicialmente de modo não-oficial por docentes e/ou pesquisadores da área, tende a envolver outras pessoas ao longo do tempo.

Dada a grande quantidade de possíveis abordagens para a área, a liderança no processo de institucionalização pode ocorrer a partir de diversos campos do conhecimento, sejam eles da sociologia, do direito, da biologia, da ecologia, das artes, etc. De toda forma, é provável que encontre ainda resistência por parte de alguns setores, e assim dependerá de um posicionamento firme e fundamentado daqueles que se disponham a liderar esse processo.

A inclusão dessa área representará, para as IES que a abriguem, um amadurecimento em termos da compreensão de questões éticas, sociais e ambientais, colocando-as em diálogo com tendências internacionais que vêm buscando esses caminhos.

\section{MARIA CASTELLANO}

Doutora em Ciência Ambiental pela Universidade de São Paulo (USP). 


\section{MARCOS SORRENTINO}

Professor Livre Docente junto à ESALQ, Universidade de São Paulo (USP). Coordenador do Laboratório de Educação e Política Ambiental - Oca nessa mesma instituição. Diretor de Educação Ambiental do Ministério do Meio Ambiente do Brasil entre 2003 e 2008.

\section{REFERÊNCIAS}

A CARNE é fraca. Produção do Instituto Nina Rosa. Direção de Denise Gonçalves. 2004. DVD (54 min). Son, color. Port. (legendado em inglês, espanhol e francês).

A TESTEMUNHA (The Witness). Produção de James LaVeck, Direção de Jenny Stein. 2000. DVD (43 min). Son, color, legendado port.

BALCOMBE, J. Pleasurable Kingdom: Animals and the Nature of Feeling Good. New York: Macmillan, 2007, $360 \mathrm{p}$.

BEKOFF, M. The Emotional Lives of Animals: a leading scientist explores animal joy, sorrow and emphaty, and why the matter. Novato, California: New World Library, 2007, $240 p$.

BLUWOL, D. Z. Ética libertária interdependente - veganismo, ecologia, saúde, política e liberdade. In: ANDRADE, S. (org.). Visão Abolicionista: ética e direitos animais. São Paulo: Libra Três, 2010, p. 73-82.

BRÜGGER, P. Para além da dicotomia abolicionismo versus bem-estarismo. Agência de Notícias de Direitos Animais, 2009. Disponível em:

<http://www.anda.jor.br/26/11/2009/para-alem-da-dicotomia-abolicionismo-versusbem-estarismo>. Acesso em: 06 jun. 2010.

BUBER, M. Eu e Tu. 2.ed. São Paulo: Cortez \& Moraes, 1979, 170 p.

CARDOZO DIAS, E. Os Animais como Sujeitos de Direito. Revista Brasileira de Direito Animal, v. 1, n.1, p.119-122, jan./dez. 2006.

. A Defesa dos Animais e as Conquistas Legislativas do Movimento de Proteção Ambiental no Brasil. Revista Brasileira de Direito animal, v. 2, n. 2, p. 123142, jan./jun. 2007.

CORMAN, L. Getting Their Hands Dirty: Raccoons, Freegans, and Urban "Trash". Journal for Critical Animal Studies, v. 9, n. 3, p.28-61, 2011. 
DEMELLO, M. Introduction to Human-Animal Studies. In: DEMELLO, M. Teaching the Animal: Human-Animal Studies across the Disciplines. Brooklyn, NY: Lantern Books, 2010, p. xi-xix.

DENIS, L. Educação Vegana: tópicos de direitos animais no ensino médio. São Paulo: Libra Três, 2012, 151 p.

DERRIDA, J. The animal that therefore I am. Critical Inquiry, The University of Chicago Press, v. 28, n. 2, p. 369-418, winter/2002.

DONOVAN, J. Feminism and the Treatment of Animals: From Care to Dialogue. Signs, v. 31, n. 2, p. 305-329, 2006. Disponível em: <http://www.jstor.org/stable/10.1086/491750>. Acesso em: 10 abr. 2013.

ENGEL JR., M.; JENNI, K. Examined Lives: Teaching Human-Animal Studies in Philosophy. In: DEMELLO, M. Teaching the Animal: Human-Animal Studies across the Disciplines. Brooklyn, NY: Lantern Books, 2010. p. 60-102.

FACWETT, L. The Case of the Mimic Octopus: Agency and World Making. Antennae, n. 21, p. 58-66, summer/2012.

FELIPE, S. T. Fundamentação ética dos direitos animais: o legado de Humphry Primatt. Revista Brasileira de Direito animal, Salvador, v. 1 n. 1, p.207-230, jan./dez 2006.

. Dos Direitos Animais aos Direitos Constitucionais: Para Além do Especismo Elitista e Eletivo. Revista Brasileira de Direito animal, Salvador, v. 2, n. 2, p. 143-159, jan./jun. 2007.

FRANCIONE, G. L. Animals - Property or Persons? Rutgers Law School (Newark) Faculty Papers, Working Paper 21, jan. 2004. Disponível em:

<http://law.bepress.com/rutgersnewarklwps/art21>. Acesso em: 03 mai. 2013.

FRANCIONE, G. L.; GARNER, R. The Animal Rights Debate: Abolition or Regulation? New York: Columbia University Press, 2010, 288 p.

FREIRE, P. Extensão ou comunicação. 8. ed. Rio de Janeiro: Paz e Terra, 1983, 136 p.

FREITAS, H. et al. O método de pesquisa survey. Revista de Administração, São Paulo, v. 35, n. 3, p.105-112, jul/set. 2000.

FUDGE, E. Animal. London: Reaktion Books, 2002, 182 p.

HERZOG, H. Are We Really a Nation of Animal Lovers? Animals and us, 2011. Disponível em: <http://www.psychologytoday.com/blog/animals-and-us/201102/arewe-really-nation-animal-lovers>. Acesso em: 09 mai. 2013. 
HSI. Animal Agriculture Should Be Included in Rio +20 Discussions, Says HSI. Humane Society International, 2012. Disponível em:<http://www.hsi.org/news/news/2012/04/united_nations_conference_rio_051512. html>. Acesso em: 08 mai. 2013.

HUMES, B. Moving toward a liberatory pedagogy for all species: Mapping the need for dialogue between humane and anti-oppressive education. Green Theory and Practice: A Journal of Ecopedagogy, v. 4, n. 1, p. 65-85, 2008.

JOY, M. Why we love dogs, eat pigs and wear cows - an introduction to carnism. Conari press: San Francisco, 2010, 216 p.

KAHN, R.; HUMES, B. Marching out from Ultima Thule: Critical counterstories of emancipatory educators working at the intersection of human rights, animal rights, and planetary sustainability. Canadian Journal of Environmental Education, v. 14, p. 179-195, 2009.

KAHN, R. Towards ecopedagogy: Weaving a broad-based pedagogy of the liberation for animals, nature and the oppressed peoples of the Earth. In: DARDER, A.; BALTODANO, M.; TORRES, R. (orgs.). The critical pedagogy reader. 2. ed. New York: Routledge, 2008, 616 p.

LEVAI, L. F. Crueldade Consentida: Crítica à Razão Antropocêntrica. Revista Brasileira de Direito Animal. Salvador: Instituto Abolicionista Animal, v. 1, n. 1, p. 171-190, jan./dez. 2006.

LIMA, J. E. R. Vozes do Silêncio. Cultura científica: ideologia e alienação no discurso sobre vivissecção. São Paulo: Instituto Nina Rosa, 2008, 192 p.

MONTGOMERY, G. M.; KALOF, L. History From Below: animals as Historical Subjects. In: DEMELLO, M. Teaching the Animal: Human-Animal Studies across the Disciplines. Brooklyn, NY: Lantern Books, 2010, p. 35-47.

NACONECY, C. Bem-Estar Animal ou Libertação Animal? Uma Análise Crítica da Argumentação Anti Bem-Estarista de Gary Francione. Revista Brasileira de Direito Animal, Salvador, v. 4, n. 5, p. 235-267, jan./dez. 2009.

NÃO MATARÁS. Produção do Instituto Nina Rosa. Imagens, direção e roteiro de Denise Gonçalves. 2006. DVD. (65 min). Son, color. Port (legendado em inglês, espanhol e francês).

PEACEABLE kingdom. Produção de James LaVeck, Direção de Jenny Stein. 2009. (70 $\mathrm{min})$. Son, color.

PEPPERBERG, I. M. Alex \& Me: How a Scientist and a Parrot Discovered a Hidden World of Animal Intelligence--and Formed a Deep Bond in the Process. New York: Harper Collins Publishers, 2008, 232 p. 
PORTER, P. Teaching Animal Movies. In: DEMELLO, M. Teaching the Animal: Human-Animal Studies across the Disciplines. Brooklyn, NY: Lantern Books, 2010, p. 18-34.

POTTS, A.; ARMSTRONG, P. Hybrid Vigor: Interbreeding Cultural Studies and Human-Animal Studies. In: DEMELLO, M. Teaching the Animal: Human-Animal Studies across the Disciplines. Brooklyn, NY: Lantern Books, 2010, p. 3-17.

REGAN, T. Jaulas Vazias: encarando o Desafio dos Direitos Animais. Porto Alegre: Lugano, 2006, 294 p.

SINGER, P. Animal Liberation. 3. ed. London, UK: Pimlico edition, 1995, 324 p. . Vida ética: os melhores ensaios do mais polêmico filósofo da atualidade. Rio de Janeiro: Ediouro, 2002, 420 p.

TERRÁQUEOS (Earthlings). Produção de Shaun Monson, Direção de Persia White, 2005. DVD (96 min). Son, color. Legendado Port.

TIMMERMAN, N.; OSTERTAG, J. Too many monkeys jumping in their heads: Animal Lessons within Young Children's Media. Canadian Journal of Environmental Education, v. 16, p. 59-75, 2011.

VEGANA. Produzido pelo Instituto Nina Rosa. Dirigido por Airon Barreto. Animação. 2010. DVD. (55 min). Son, P\&B. Port. Sem legendas. 